\title{
Canadian recommendations for critical care ultrasound training and competency
}

\author{
Robert T Arntfield MD FRCPC 1 , Scott J Millington MD FRCPC ${ }^{2}$, Craig D Ainsworth MD FRCPC ${ }^{3}$, \\ Rakesh C Arora MD FRCSC ${ }^{4}$, John Boyd MD FRCPC ${ }^{5}$, Gordon Finlayson MD FRCPC ${ }^{5}$, William Gallagher MD FRCPC ${ }^{6}$, \\ Colin Gebhardt MD FRCPC ${ }^{7}$, Alberto Goffi MD ${ }^{8}$, Edgar Hockmann MD FRCPC ${ }^{8}$, \\ Andrew W Kirkpatrick MD FRCSC ${ }^{9}$, Robert C McDermid MD FRCPC ${ }^{9}$, Jason Waechter MD FRCPC ${ }^{9}$, \\ Natalie Wong MD FRCPC ${ }^{8}$, Samara Zavalkoff MD FRCPC ${ }^{10}$, Yanick Beaulieu MD FRCPC ${ }^{11}$; \\ for the Canadian Critical Care Society
}

RT Arntfield, SJ Millington, CD Ainsworth, et al. Canadian recommendations for critical care ultrasound training and competency for the Canadian Critical Care Society. Can Respir J 2014;21(6):341-345.

OBJECTIVE: To achieve national consensus on standards of training, quality assurance and maintenance of competence for critical care ultrasound for intensivists and critical care trainees in Canada using recently published international training statements.

DATA SOURCES: Existing internationally endorsed guidelines and expert opinion.

DATA SYNTHESIS: In November 2013, a day-long consensus meeting was held with 15 Canadian experts in critical care ultrasound in which essential topics relevant to training ultrasound were discussed.

CONCLUSIONS: Consensus was achieved to direct training curriculum, oversight, quality assurance and maintenance of competence for critical care ultrasound. In providing the first national guideline of its kind, these Canadian recommendations may also serve as a model of critical care ultrasound dissemination for other countries.

Key Words: Competence; Consenus statement; Critical care ultrasound; Echocardiography; Training

\section{EXECUTIVE SUMMARY}

The patterns of use and dissemination of critical care ultrasound (CCUS) are variable among centres in Canada; thus, an expert consensus guiding the provision of training and achievement of competency is needed.

\section{Recommendations}

Adoption of existing consensus statements:

The recommendations contained in the present Canadian consensus statement follow directly from two previously published, internationally endorsed CCUS consensus statements. A strong working knowledge of these statements is essential to understanding and implementing the present document.

1. The American College of Chest Physicians (ACCP)/Société de Réanimation de Langue Française (SRLF) consensus document (1) should form the basis for the scope of CCUS practice in Canada, defining CCUS itself and determining what specific applications fall within its purview. Of the CCUS examination types outlined in the ACCP document, the Canadian expert panel distinguishes between core applications (basic cardiac, lung and pleura, guidance of vascular access, and detection of free abdomen fluid) and optional applications (diagnosis of venous thrombosis, renal and abdominal aorta).

\section{Les recommandations canadiennes relatives à la formation et aux compétences sur les échographies en soins intensifs pour la Société canadienne de soins intensifs}

OBJECTIF : Obtenir un consensus national sur les normes de formation, d'assurance-qualité et de maintien des compétences sur les échographies en soins intensifs chez les intensivistes et les stagiaires en soins intensifs au Canada à l'aide de documents de principes internationaux publiés récemment.

SOURCES DES DONNÉES : Directives et avis d'experts approuvés sur la scène internationale

SYNTHÈSE DES DONNÉES : En novembre 2013, une réunion de consensus d'une journée a réuni 15 experts canadiens sur les échographies en soins intensifs au cours de laquelle ils ont traité de sujets essentiels liés à la formation sur les échographies.

CONCLUSIONS : Les experts sont parvenus à un consensus sur le programme de formation directe, la supervision, l'assurance-qualité et le maintien des compétences sur les échographies en soins intensifs. Ces recommandations canadiennes, qui sont les premières directives nationales du genre, pourraient également servir de modèle de diffusion des données sur les échographies en soins intensifs dans d'autres pays.

2. The Vienna conference consensus document (2), an internationally endorsed guideline on training principles in CCUS, should form the basis for the creation of local CCUS training in Canada and determine how learners' instruction should be organized.

\section{General principles:}

1. Dissemination of CCUS at the Canadian level should focus on the implementation of existing descriptions of objectives and content $(1,2)$.

2. High-quality educational materials to learn CCUS are abundantly available, and it is not the immediate priority of the present panel to author new educational content.

3. The recommendations put forth in the present document are based on expert opinion because there is currently a lack of high-quality outcomes data related to CCUS; by assisting in the creation of a broad base of CCUS users, the present guidelines are expected to facilitate the conduct of such outcomes research.

4. The current scope of the present document is to address CCUS training for current providers of critical care medicine (trainees and attending physicians) and the immediate scope will not address junior residents, medical students or specialties outside of critical care medicine.

${ }^{1}$ Division of Critical Care Medicine, Western University, London; ${ }^{2}$ University of Ottawa, Ottawa; ${ }^{3}$ McMaster University, Hamilton, Ontario; ${ }^{4}$ Cardiac Sciences Program, University of Manitoba, Winnipeg, Manitoba; ${ }^{5}$ University of British Columbia, Vancouver, British Columbia; ${ }^{6}$ Dalhousie University, Halifax, Nova Scotia; ${ }^{7}$ University of Saskatchewan, Saskatoon, Saskatchewan; ${ }^{8}$ University of Toronto, Toronto, Ontario; ${ }^{9}$ Department of Critical Care Medicine, University of Calgary, Calgary, Alberta; ${ }^{10}$ McGill University; ${ }^{11}$ University of Montreal, Montreal, Quebec

Correspondence: Dr Robert Arntfield, Division of Critical Care Medicine, Western University, Victoria Hospital, 800 Commissioners Road East, D2-521A, London, Ontario N6A 5W9. Telephone 519-685-8786, e-mail robert.arntfield@gmail.com 
5. The recommendations contained within the present document are intended to be applied to all critical care environments in Canada regardless of size, and to include both community and academic settings.

6. The present document will be iterative in nature, and will evolve with the landscape of CCUS in Canada.

\section{CCUS training:}

1. Education and oversight is best achieved on a local level with local experts overseeing the education of learners pursuing CCUS training.

2. Competency assessment and feedback should be provided to learners throughout their training. Until robust and valid assessment tools are developed, competency is best assessed by a local expert within the scope of the ACCP and Vienna consensus documents.

3. Significant gaps exist within the literature relating to educational aspects of CCUS; by assisting in the creation of a broad base of CCUS users, the present guidelines are expected to facilitate the conduct of educational research.

\section{Quality assurance and maintenance of competence:}

1. It is incumbent on each user of CCUS to engage in the quality assurance processes implemented by the local expert.

2. It is incumbent on each user of CCUS to ensure maintenance of competency by participating in continuing medical education.

\section{INTRODUCTION}

Point-of-care ultrasound refers to an ultrasound examination performed directly by the treating provider to answer a well-defined question relevant to the immediate care of a patient. It differs from traditional ultrasound in that it is goal directed (rather than comprehensive) and in that it enables the provider to integrate anatomical and functional ultrasound findings into their diagnostic and therapeutic algorithms in real time.

CCUS refers to point-of-care ultrasound applied in the context of caring for critically ill patients. The assertion that CCUS is essential to the contemporary practice of critical care medicine has been endorsed by 13 national-level critical care societies (2), including the Canadian Critical Care Society. International recommendations have emphasized the need for individual countries and critical care societies to develop training frameworks that are tailored to meet the needs of local constituents (2).

In Canada, instruction and utilization of the CCUS skill set is variable among centres. There is currently no clear consensus on how practitioners should be trained or achieve competency in CCUS. Without a national-level consensus on training methods, CCUS instruction will continue to vary significantly among institutions as will the skill level of individual providers, making a national standard of care difficult to define.

The primary goal of the present consensus statement is to provide a set of recommendations to guide the dissemination, training and achievement of competency in CCUS among all Canadian critical care providers.

There is a series of secondary goals that may be facilitated by adoption of the recommendations contained herein:

1. To improve patient care and safety by facilitating the creation of a large pool of competent CCUS providers;

2. To facilitate high-quality educational research by enabling the creation of a large pool of competent CCUS providers; and

3. To foster high-quality outcomes research by facilitating the creation of a large pool of competent CCUS providers.

\section{Needs identification}

\section{METHODS}

In the fall of 2012, the Canadian Critical Care Society initiated a planning process to discuss a national strategy for CCUS. An open workshop was held in March 2013 in Vernon, British Columbia, and critical care department heads from each Canadian academic centre were contacted and asked to provide the names of local CCUS experts and other relevant stakeholders. The agenda of the meeting was set to address the following issues: central versus local administration of training, scope of CCUS practice in Canada, training course requirements, definition of competency and comparative models of ultrasound dissemination.

Informed by the initial round of discussion, an executive group of three members (RA, SM, YB) generated a draft consensus document that was subsequently circulated to the expert panel members. The draft document was revised over several iterations to reflect the feedback of the group in preparation for a final meeting.

\section{Expert panel meeting}

After several cycles of feedback and revision, 15 experts in CCUS and CCUS education representing seven Canadian provinces met in November 2013 in Toronto, Ontario. In a meeting of the entire panel, the contents of the draft consensus document were reviewed and refined. Consensus was achieved on all major issues. Following the meeting, the executive group incorporated these modifications and circulated the revised document to all panel members for final approval. The finalized document was sent to the Canadian Critical Care Society executive for review and endorsement.

\section{RESULTS}

The recommendations of the expert panel regarding the training process for CCUS are detailed herein.

\section{Framework for CCUS training}

Centre requirements: For a centre to implement and maintain a program in CCUS, the minimum requirements are:

1. Commitment by the hospital and critical care program to create and sustain a local CCUS program;

2. Support from the hospital and critical care department to sustain and/or train local CCUS expert(s); and

3. At least one ultrasound machine in the intensive care unit (ICU), dedicated for use by critical care providers for CCUS applications.

Local experts: All centres require a local expert to oversee CCUS. Local experts must:

1. Be an attending critical care physician;

2. Be knowledgeable and experienced in CCUS, including general CCUS and basic critical care echocardiography, in accordance with the ACCP consensus document (1); and

3. Be supported with time and funding by their hospital/department to perform CCUS.

The requirements to be a local expert consist of a combination of background training, experience and endorsement from the local critical care director. While it is acknowledged that the experience and background training of local experts will vary across centres, all should have competence in the skills outlined in the ACCP consensus document.

In some centres, physicians who lack experience or knowledge will require additional training before taking on the role of a local expert. In cases for which no local expert exists, it is incumbent on the ICU director to support a candidate in developing the above-mentioned attributes. Mentorship and collaboration with other local experts, including those from other disciplines, may also be important in the development of these abilities. It is acknowledged that telementoring and remote supervision may, in the future, facilitate this process.

\section{Pathway to achieving competency in CCUS}

For centres with a local expert and the necessary resources described above, the training pathway outlined in Figure 1 should serve as a model. Introductory training: With many academic and commercial courses available, it is not the priority of the present panel to recommend specific content or to create new educational material. Instead, it is 
emphasized that the initial training phase must address all of the core competencies of CCUS as outlined in the ACCP consensus document.

At a minimum, it is believed that introductory training should have the following characteristics:

1. Content consistent with the scope of the ACCP consensus document;

2. Devotes sufficient time to each component of CCUS (see Intensity of Introductory Training below);

3. Course director is a physician who practices critical care medicine in an ICU setting;

4. Course instructors are competent in point-of-care ultrasound and teach within the scope of the ACCP consensus document; and

5. Appropriate hands-on time and student:faculty ratios (ideally $3: 1$ or less) per ultrasound machine are preserved.

Intensity of introductory training: The Vienna consensus statement (2) recommends at least $10 \mathrm{~h}$ of general CCUS training (combined hands-on and didactic) and at least 10 additional hours of basic critical care echocardiography training (combined hands-on and didactic). The didactic elements may consist of standard lecture format and/or e-learning. It is recognized that individual learners will require a variable duration of introductory course work; thus, the specific training duration should be tailored to the individual learner.

Portfolio building: Following introductory training, a portfolio-building phase should be undertaken to develop experience in CCUS. The duration of time and number of studies required to develop competency will vary by individual learner; however, suggested benchmarks are included in this pathway to guide learners and educators. The ability to tailor the intensity of training to the learner relies on regular supervision and feedback from the local expert.

Supervision model: Supervision is required during the portfolio-building phase to provide education, to continuously evaluate competency and to ensure patient safety. The recommended approach is for ultrasound examinations to be acquired by the learner scanning in real time with the local expert at the bedside. This allows for direct observation and immediate feedback. Given the current limitations in the supply of local experts, it is acknowledged that an offline approach to supervision may be necessary, especially in the context of larger centres with multiple learners. In this model, the trainee may digitally store videos and still images from their examinations to be reviewed at a later time with the local expert. Timely review and feedback is imperative.

A blended model of both direct and offline ultrasound examination supervision may be the most realistic approach to early training. Where possible, scans performed earlier in the portfolio-building process should be prioritized for direct supervision, with offline review used more frequently as experience accrues. As the number of competent CCUS providers at a given institution increases, the number and availability of local experts to supervise portfolio training will grow in parallel.

Number of required studies: The goal of the portfolio-building phase is to provide a structured, hands-on experience to ensure a minimum level of competency and experience with CCUS. The limitations of a number-driven approach are acknowledged. While it is essential that the specific training experience be tailored to each individual learner, it is recommended that a minimum number of supervised studies be performed by the learner, as follows:

- Basic critical care echocardiography: 30 studies;

- Lung and pleural ultrasound: 20 studies;

- Guidance of vascular access: 10 studies;

- Detection of abdominal free fluid: 10 studies;

- Renal ultrasound: 25 studies;

- Abdominal aorta: 25 studies; and

- Diagnosis of venous thrombosis: 25 studies.

Core versus optional examination applications:

It is accepted that each of these examination types can have significant utility to critical care providers. It is further recognized that
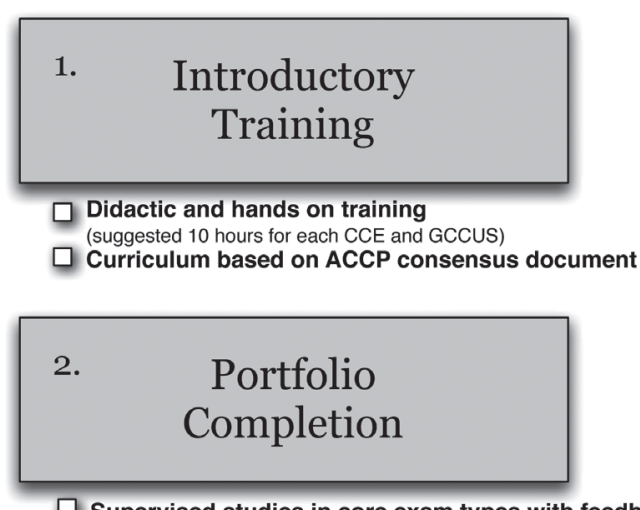

$\square$ Supervised studies in core exam types with feedback

Suggested number of studies (will vary by individual)

-----Basic critical care echo: 30

----Lung and pleura: 20

---Guidance of vascular access:10

-Abdominal free fluid: 10

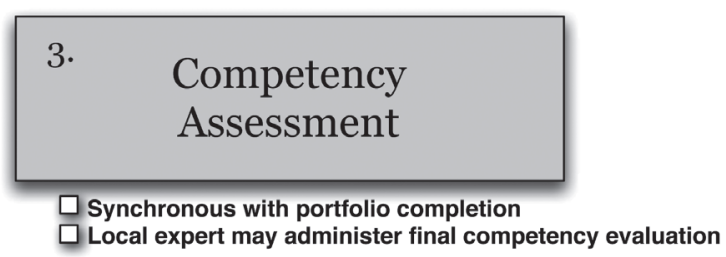

\section{Quality Assurance \& Maintenance of Competence}

$\square$ Locally driven QA mechanisms

$\square$ Continuing medical education

Figure 1) Proposed training pathway. ACCP Americal College of Chest Physicians; CCE Critical care echocardiography; GCCUS General critical care ultrasound; QA Quality assurance

certain examination types are of universal benefit whereas some applications may, depending on local factors, be less critical. As such, the above applications have been divided into two categories: core and optional applications.

\section{Core applications (Table 1):}

1. Basic critical care echocardiography;

2. Lung and pleural ultrasonography;

3. Guidance of vascular access; and

4. Identification of free abdominal fluid.

Optional applications (Table 2):

1. Diagnosis of venous thrombosis;

2. Renal ultrasound; and

3. Abdominal aorta.

Core studies should be included in every CCUS training program. Optional examination types may be included at the discretion of the local expert.

Nature of studies (simulation, standardized patients and ICU patients): Studies credited toward the learner's portfolio should be acquired on critically ill patients, because this is most representative of the environment in which the learner will be practicing.

The use of simulators or standardized patients in controlled circumstances such as workshops offer excellent opportunities for training, but these scans should not be credited toward the portfolio requirements. 
TABLE 1

Core critical care ultrasound examination types and components

\begin{tabular}{|c|c|c|}
\hline Examination type & Description & Required views \\
\hline $\begin{array}{l}\text { Basic critical care } \\
\text { echocardiography }\end{array}$ & $\begin{array}{l}\text { A basic critical care echocardiogram consists of } 5 \text { core views that are required } \\
\text { for each examination in the learner's portfolio }\end{array}$ & $\begin{array}{l}\text { Parasternal long axis } \\
\text { Parasternal short axis at papillary muscle level } \\
\text { Apical four-chamber view } \\
\text { Subcostal four-chamber view } \\
\text { Long axis view of the inferior vena cava }\end{array}$ \\
\hline $\begin{array}{l}\text { Lung and pleural } \\
\text { (thoracic) }\end{array}$ & $\begin{array}{l}\text { A thoracic study consists of both pleural and lung assessment. Each thoracic } \\
\text { study must assess at least } 4 \text { points on each hemithorax (for a total of } \\
8 \text { views) }\end{array}$ & $\begin{array}{l}\text { Lung } \\
\text { Anterior chest wall } \\
\text { Anterolateral chest wall } \\
\text { Pleural } \\
\text { Posterosuperior chest wall } \\
\text { Posteroinferior chest wall }\end{array}$ \\
\hline $\begin{array}{l}\text { Guidance of vascular } \\
\text { access }\end{array}$ & $\begin{array}{l}\text { For ultrasound-guided vascular access, real-time visualization of the vessel to } \\
\text { be cannulated in addition to relevant neighbouring structures is required. } \\
\text { Thrombosis at the site of catheter insertion must be excluded }\end{array}$ & $\begin{array}{l}\text { Short axis image representative of the relationship of the } \\
\text { relevant vessel to neighboring structures } \\
\text { Long axis view of vessel with guidewire in situ }\end{array}$ \\
\hline $\begin{array}{l}\text { Identification of free } \\
\text { abdominal fluid }\end{array}$ & $\begin{array}{l}\text { This study is directed at assessing for large-volume ascites and/or guiding its } \\
\text { drainage. This is distinct from trauma ultrasound (the FAST examination), } \\
\text { which requires greater sensitivity and a greater number of portfolio studies } \\
\text { (50 according to current Canadian standards [3]). }\end{array}$ & $\begin{array}{l}\text { Right upper quadrant view } \\
\text { Left upper quadrant view } \\
\text { Suprapubic view }\end{array}$ \\
\hline
\end{tabular}

FAST Focused assessment with sonography for trauma

The portfolio phase is intended to increase skill to the level required to consistently meet the challenge of image acquisition and interpretation in a critical care environment, with all its inherent difficulties.

Examination type components: The examination types and their requisite components for the core and the optional CCUS examination types are detailed in Table 1 and Table 2.

Logging the portfolio: Record keeping is required as part of the portfoliobuilding process. The method by which the portfolio is maintained will depend on each centre's resources, and may range from paperbased documentation to more complex digital archiving systems.

\section{Assessment of competency}

Competency should be assessed continuously as the local expert guides the learner through the portfolio-building phase with timely ongoing feedback. On completion of their portfolio development, each learner should also receive a final assessment that ensures competency in image acquisition, image interpretation and clinical integration as determined by the local expert and the ACCP competency statement. The absence of validated assessment tools for CCUS competency is a current limitation in both the formative and summative evaluation processes.

Maintenance of competence: As in all other areas of clinical medicine, ensuring ongoing proficiency in both the cognitive and procedural aspects of CCUS requires a commitment to continuing medical education. Professional development for CCUS can be achieved in a variety of ways, including institutional CCUS image review sessions, attendance at CCUS courses or lectures, or provision of CCUS education and quality assurance locally (see below).

A provider previously deemed competent in CCUS who has a prolonged absence from routine use should consider a period of retraining and portfolio acquisition, the structure and duration of which should be at the discretion of the local expert.

Quality assurance

A quality assurance (QA) process is required for all programs to ensure that CCUS is being applied in a manner that consistently prioritizes patient safety. This process may take on various forms, at the discretion of the local expert, including:

1. Review of archived images by the local expert and/or other CCUS providers;

2. Group image review conferences; and

3. Comparing CCUS results with those of other diagnostic modalities.
The QA process is especially important for CCUS novices, and the local expert or their designate must take an active role in reviewing the images and reports generated by their learners. In most cases this will be a dynamic process, with intensity of oversight being influenced by provider experience and entrustability with the modality.

It is incumbent on all providers who use CCUS to engage in QA. Processes must be put in place to detect and review incidents where CCUS studies are deemed inaccurate or otherwise substandard. This may also include cases where CCUS was not used where it might have reasonably been expected to influence management. For providers or learners who are unable to meet the standards set by the local expert, a process to modify or restrict access to CCUS while remediation is performed should be in place.

\section{PEDIATRIC CONSIDERATIONS}

Given the specific challenges to pediatric critical care practice, the recommendations for CCUS training differ somewhat from adult critical care. The general recommendations and training pathway (Figure 1) presented in this document still apply to pediatric practice, with some variations as described below.

The following should be considered for pediatric CCUS:

- At present, there are few available pediatric-focused introductory training options. Pediatric practitioners can complete a general (nonpediatric) CCUS training course to satisfy the initial step in the CCUS training pathway.

- When undertaking a cardiac assessment, the pediatric practioner must appreciate that there is a much broader range of anatomical abnormalities in congenital heart disease when compared with acquired heart disease in adults; this can make interpretation more difficult. Pediatric practitioners should remain focused on a goaldirected examination, integrate their findings with other clinical information, and maintain a low threshold to obtain a comprehensive echocardiogram.

- The relevant examination types for pediatrics differ from adults:

Core applications:

1. Basic critical care echocardiography

2. Lung and pleural ultrasonography

3. Guidance of vascular access 
TABLE 2

Optional critical care ultrasound examination types and components

\begin{tabular}{|c|c|c|}
\hline Examination type & Description & Required views \\
\hline Renal & $\begin{array}{l}\text { The focused renal assessment for hydronephrosis should } \\
\text { consist of the assessment of each kidney in } 2 \text { planes }\end{array}$ & $\begin{array}{l}\text { Long axis view of kidney (bilaterally) } \\
\text { Short axis view of kidney (bilaterally) }\end{array}$ \\
\hline Abdominal aorta & $\begin{array}{l}\text { To exclude an abdominal aortic aneurysm, multiple } \\
\text { segments of the abdominal aorta must be visualized }\end{array}$ & $\begin{array}{l}\text { A continuous short axis sweep of the aorta from celiac axis to the aortic } \\
\text { bifurcation } \\
\text { OR } \\
5 \text { separate views from the aorta in short axis, representative of the length of } \\
\text { the abdominal aorta from celiac axis to the aortic bifurcation }\end{array}$ \\
\hline $\begin{array}{l}\text { Diagnosis of venous } \\
\text { thrombosis }\end{array}$ & $\begin{array}{l}\text { A lower-extremity deep venous thrombosis assessment } \\
\text { consists of two-dimensional visualization and compression } \\
\text { of the proximal lower extremity veins bilaterally in short } \\
\text { axis }\end{array}$ & $\begin{array}{l}\text { Common femoral vein at inguinal canal } \\
\text { Common femoral vein at greater saphenous vein insertion } \\
\text { Common femoral vein at lateral perforator take off } \\
\text { Common femoral vein bifurcation to superficial and deep femoral vein } \\
\text { Proximal popliteal vein } \\
\text { Popliteal vein just proximal to trifurcation }\end{array}$ \\
\hline
\end{tabular}

Optional:

4. Identification of free abdominal fluid

5. Diagnosis of venous thrombosis

6. Renal ultrasound

Nonrelevant examinations:

7. Abdominal aorta

\section{DISCUSSION}

The introduction of CCUS into the worldwide critical care milieu has proceeded rapidly, to the point where its role as a fundamental component of contemporary practice is supported by all major critical care societies. Like most industrialized countries, Canada has faced challenges in introducing this skill set in an efficient manner while ensuring patient safety. The goal of the present consensus statement is to provide a set of recommendations to guide the dissemination, training, and achievement of competency in CCUS among Canadian critical care providers.

The foundation for the present document is outlined by the ACCP/SRLF (1) and Vienna (2) consensus documents, both of which have been widely endorsed internationally. The former document clearly outlines the specific skills required for CCUS, and suggests that mastery of these individual skills defines the achievement of competence in CCUS. The Vienna document provides guidelines for the specific training methods required to achieve CCUS competence, and importantly, frames the purpose of this document. It is "the role of each critical care society to support the implementation of training" in its own country (2).

The Canadian expert panel adhered to the recommendations of the ACCP/SRLF and Vienna consensus documents very closely; indeed, only two significant alterations were proposed. To reflect the specific practice landscape in Canada, it was believed to be optimal to divide the specific CCUS applications into core (Table 1) and optional (Table 2) examination types. This distinction allows for a slightly narrower focus to maximize dissemination of the applications believed to be most crucial, while empowering each individual centre to apply the optional applications as appropriate. The other notable deviation from the ACCP/SRLF consensus statement was the inclusion of pediatric CCUS training considerations. Asserting the value of CCUS in the pediatric patient, our recommendations describe a scope of core examination types matched to this population's most frequent pathologies in the critical care setting.

A point of particular importance is the recommendation that curriculum administration and assessment of competence be performed locally. While adherence to the recommendations contained in the present document will ensure national consistency, allowing for flexibility at the level of the individual institution under the guidance of a local expert is believed to be preferable to a centrally administered model. Centralized models carry additional financial costs and administrative complexity that, at this time, would create additional barriers to dissemination of CCUS.

The approach to CCUS dissemination proposed by the present document has several limitations. Emphasizing a decentralized approach will result in heterogeneity among centres, and the individual local experts will necessarily be variable in their experience and expertise. The second limitation involves the attainment of individual competence in CCUS. While the ACCP document clearly defines the individual learning objectives, the current deficit in educational literature relating to point-of-care ultrasound means that the optimal instructional methods are currently unknown for most CCUS applications. Furthermore, there are currently no validated tools to assess competence in this area; as such, the determination of competence is left to the discretion of the local expert, much as it is for the vast majority of clinical skills in all other areas of medicine.

\section{CONCLUSION}

The rapid introduction of CCUS into the practice of critical care medicine presents significant barriers to dissemination. The recommendations contained within the present document reflect the current expertise in performance and training of CCUS across Canada. They aim to guide the dissemination, training, and achievement of competency in CCUS among Canadian critical care providers in a safe and efficient manner.

DISCLOSURES: No financial support was used for this consensus document. This work was performed as an interinstitutional collaborative carried out during the Canadian Critical Care Forum meeting, November 10, 2013, in Toronto, Ontario.

\section{REFERENCES}

1. Mayo PH, Beaulieu Y, Doelken P, et al. American College of Chest Physicians/La Société de Réanimation de Langue Française statement on competence in critical care ultrasonography. Chest 2009;135:1050-60.

2. Cholley BP, Mayo PH, Poelaert J, et al. International expert statement on training standards for critical care ultrasonography. Intensive Care Med 2011;37:1077-83.

3. Canadian Emergency Ultrasound Society, Recommended Standards of Independent Practitioner Training. < www.ceus.ca/002-

standards/002-00.standards.htm>. (Accessed November 14, 2013). 


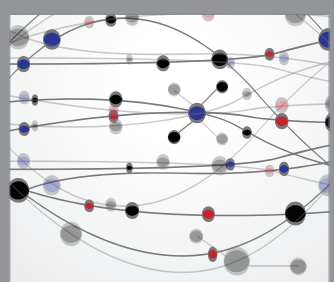

The Scientific World Journal
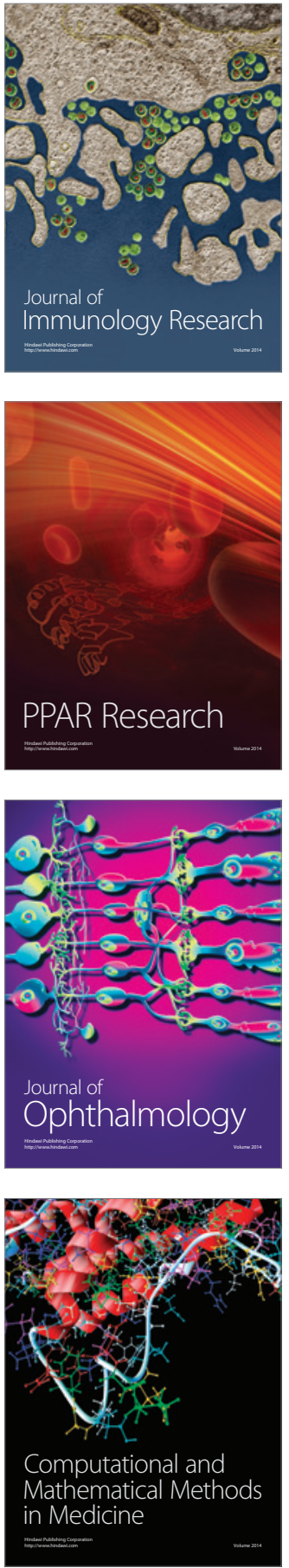

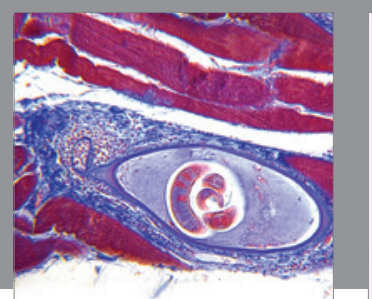

Gastroenterology Research and Practice

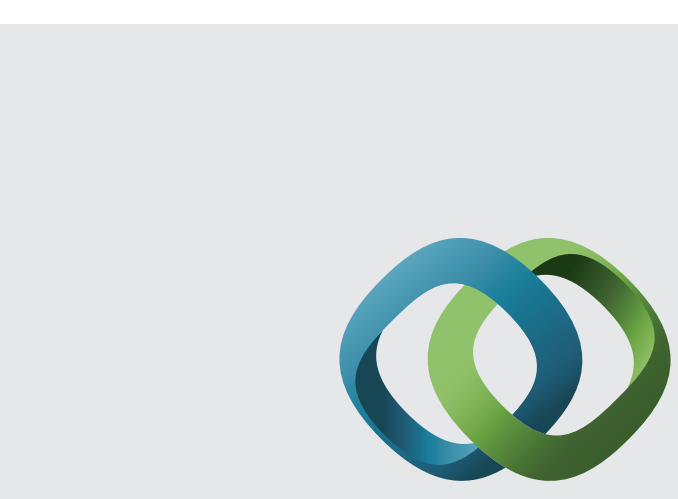

\section{Hindawi}

Submit your manuscripts at

http://www.hindawi.com
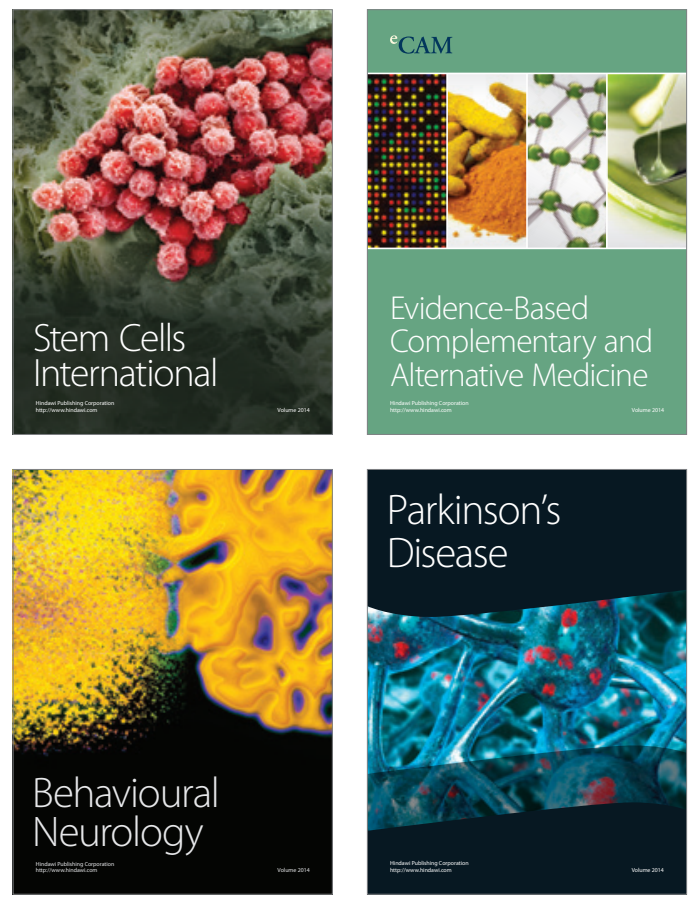
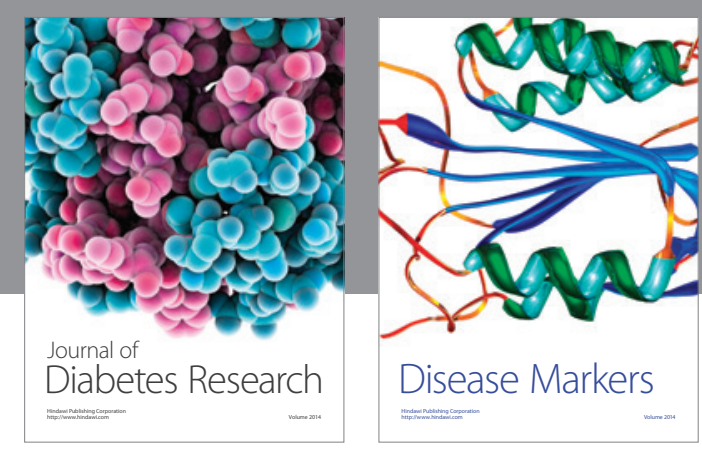

Disease Markers
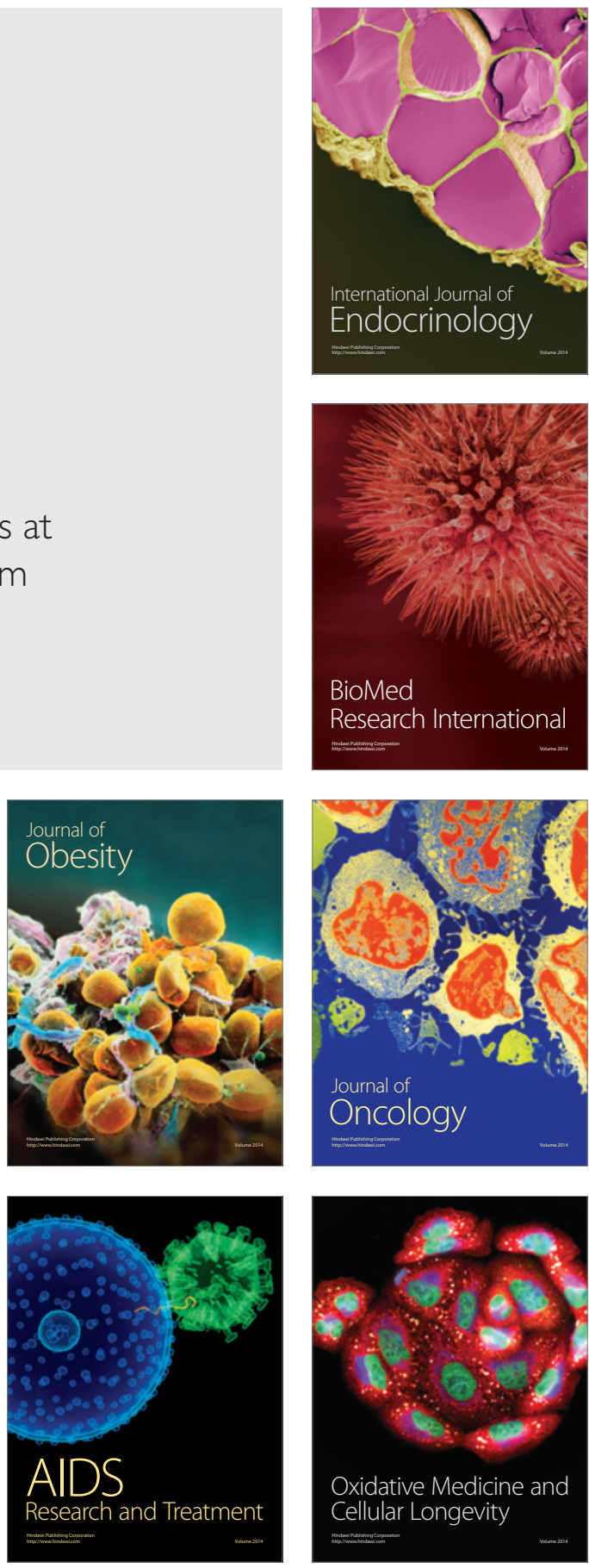